\title{
Change in reproductive and dispersal traits in the water strider, Aquarius paludum (Fabricius) and global warming
}

\author{
Tetsuo Harada*, Takashi Shiraki, Shiho Takenaka, Takero Sekimoto, Kentaro Emi, \\ Tomoya Furutani \\ Laboratory of Environmental Physiology, Graduate School of Integrated Arts and Sciences, Kochi University, Kochi, Japan; \\ *Corresponding Author: haratets@kochi-u.ac.jp
}

Received 6 December 2012; revised 8 January 2013; accepted 20 January 2013

\begin{abstract}
This study aims to examine the following three hypotheses on the impact of global warming on the populations of the water strider, Aquarius paludum in the Kochi-Nankoku area $\left(33^{\circ} 30^{\prime} \mathrm{N}\right)$ of Kochi prefecture, Japan through the recent data collected in 2009-2011. 1) Has the generation number increased? 2) Has aestivation appeared in adults? 3) Have overwintering adults stopped dispersing between the water surface and overwintering lands-sites far away from water and, instead, overwintered on/near the shore? Sampling data showed that the number of generations may have increased from three (1989-2002 strains) and four (2004-2008) to five (2009-2011) per year in Kochi $\left(33^{\circ} \mathrm{N}\right)$. The ratio of adults having well developed flight muscles decreased from $45 \%$ in 1995 to $24 \%-28 \%$ in $2009-2011$ in overwintering adults collected from the field in fall likely as a result of histolysis. "Mosaic-typed" wing morph group with long fore-wings and short hind-wings newly appeared in 2009-2011 in the Kochi-Nankoku overwintering populations. The mosaic-typed wings group cannot fly and the black and long fore wings might function as absorbing apparatus of sun-lights in the daytime of winter. Some overwintering adults seem to stop migrating between water bodies and overwintering sites on land far from the water bodies and overwinter, instead, near the shore. The use of Aquarius paludum as a biological indicator would be possible in the future, because this species can respond and change their reproductive and dispersal characteristics to the global change.
\end{abstract}

Keywords: Adult Diapause; Aestivation; Dispersal; Long Fore-Wing and Short Hind-Wing;
Semi-Aquatic Bug; Voltinism

\section{INTRODUCTION}

The impact of global warming on the lives of insects were discussed by several entomologists up to date [1-9]. The following four categories would be possible for the impact insects. A northern shift in distribution is the first [10]. As the second, mismatching between herbivorous insects and their host plants including the temporal mismatches in pollination interactions between plants and pollinators [8] sometimes occurs as the result [11]. For example, a pronounced mismatch of the current niche spaces is exhibited by the butterfly, Boloria titania and its host plant, Polygonum bistorta [6]. The impact on the relationship between insect vectors and the pathogens of diseases is the third pattern, which include malaria [5] [12]; West Nile fever [13] and modeling for vector-borne infections in general [14], leading to spreading to new latitude and altitude areas sometimes, and in some cases, to metropolis as the result of heat island phenomena. Another example of the meltdown of mutualism between insects and bacteria was shown by [15]. As the fourth pattern, the life history could be modified to fit the new warming meteorological condition. For example, the voltine-number may increase due to a prolonged season for the active life history status of reproduction and embryonic/larval development, as a fourth pattern [16]. Another example, the ovipositing season for a cicada, Cryptotympana facialis is in advance from after the rainy season (beginning of 20th century) to the mid rainy season (late 20th Century) as the adaptation of drying up the soil as the oviposition place due to the global warming [17]. Moreover, duration of prepupal summer dormancy regulates synchronization of adult diapause with winter temperatures which have been changed due to the global warming in bees of the genus, Osmia [18].

Aquarius paludum (Fabricius) is included in Gerridae, 
Heteroptera and a water bug inhabiting fresh water bodies and distributed over a wide area of the Palearctic zone from England to Japan (western and eastern limits) and from the southern part of Siberia to India (northern and southern limits) [19]. Photoperiodic responses of the Kochi $\left(33^{\circ} 30^{\prime} \mathrm{N}\right)$ population of $A$. paludum were examined for wing-form determination and induction of adult diapause, two decades ago (1989-1991). Short-days induced 100\% long-winged and 100\% diapause adults, whereas long-days induced $60 \%$ short-winged and $100 \%$ reproductive adults. The critical photoperiod for diapause induction was $13 \mathrm{~h}$ light-11 h dark (13 L-11 D) and for wing-form determination was 13.75 L-10.25 D [20]. The critical values shifted to longer values of 15 L-9 D for wing-form and 14 L-10 D for diapause under gradually shortening photoperiods [20]. Short-days promote high flight propensity and keep flight muscles of insects matured, whereas long-days during the larval stage inhibit flight propensity and promote flight muscle histolysis before the 40th imaginal day [21]. Moreover, increasing photoperiods even in the range beneath the critical photoperiod lead to less flight activity and promote flight muscle histolysis [21]. The response to changing photoperiods (both decreasing and increasing) disappeared completely and the critical photoperiods for wing-form determination and diapause induction shortened by more than 30 minutes, a decade ago (1999-2002) [22].

Sampling data showed that the number of generations have increased from three (1989-2002 strains) to four or more (2004-2008) per year in Kochi-Nankoku populations $\left(33^{\circ} 30^{\prime} \mathrm{N}\right)$ [23]. The extent of photoperiodic response for diapause induction was diminished for the population collected in 2007 as shown by a rearing experiment [23]. Such a diminished response could lead to partial concomitant disappearance of diapauses. Aestivation seems to be adopted by a portion of adults in the Nankoku-Kochi population (both sexes) as shown by examinations of ovaries and testes in 2008 [23]. Overwintering adults collected from the field in fall of 2008 no longer had flight muscles, likely as a result of histolysis [23]. However, it is not clear whether such several signs of dramatic change of life history traits are temporal only in 2007-2008 or permanent. Similar data in 2009-2011 remain for this question to be solved.

This study tries to solve the question: whether change in reproductive and dispersal traits in accordance with global warming are continuing in 2009-2011.

\section{MATERIALS AND METHODS}

\subsection{Samplings}

Every 2 weeks from January to December in 2009, 2010 and 2011, timed-catch sampling was performed in an agricultural waterway with width of about $2 \mathrm{~m}$ located in the area between Kochi City and its eastern neighbor, Nankoku City $\left(33^{\circ} 31^{\prime} \mathrm{N}, 133^{\circ} 36^{\prime} \mathrm{E}\right)$ that is critical for supplying water to paddy fields. One hundred sweeps for $40 \mathrm{~min}$. were involved in timed-catch sampling using a $30 \mathrm{~cm}$ diameter round-shaped net with a $1 \mathrm{~m}$ long stick. Soon after the number of instars, sex and wing length were recorded, samples were released. More than 10 pairs of adults were collected from the Kochi-Nankoku population and taken to the laboratory for dissection to examine the reproductive and dispersal organs (ovaries and testes, flight muscles) in 2009, 2010 and 2011.

\subsection{Flight Muscle Rank and Reproductive Diapause}

There are three ranks in the extent of flight muscle development to be judged (1: complete histolysis, 2: partial development or histolysis, 3: completely matured) according to the criteria described in Inoue and Harada [21]. Based on the maturation of reproductive organs on the 30th day after emergence, it was judged whether adults had entered reproductive diapause. If a female had laid no eggs during the first 30 days after the emergence and, in addition, had no mature ööcytes on the 30th day, she was judged to have entered reproductive diapause [20]. The estimation of an index of testes volume was done using [(diameter of testis $\times 0.5)^{2} \times \pi \times$ testis length, $\mathrm{mm}^{3}$ ] [25]. If a male showed a testes volume index (average of right and left testes) of less than $0.01 \mathrm{~mm}^{3}$ on the 30th day after adult emergence, he was judged to be in reproductive diapause (Harada et al., 2011) [23].

\subsection{Statistical Analysis}

SPSS (12.0 J for windows) software was used for statistical analysis. Mann-Whitney U-test and ANCOVA were used for simple and integrated analysis, respectively. For the analysis of the comparison in \% diapause as field sampling data between 1995-1997 and 2009-2011, Fisher's Exact Probability test was used. For the analysis of the comparison in flight muscles ranks as field sampling data between 1995 and 2009-2011.

\section{RESULTS}

\subsection{Samplings}

According to the 2010 sampling of larvae from the waterway (Kochi-Nankoku population), recruitment of new generation adults occurred five times in mid and late May, late July to early August, late August and early September, late September and early October, and late November to December (Figure 1) (Table 1). Harada et al. [26], Harada et al. [22] and Harada et al. [23] estimated that the generation number of the Kochi-Nankoku population in 1995-1997, 2004 and 2008 was three, 
three-four and four-five, respectively.

\subsection{Comparison of Reproductive Maturation in the Kochi-Nankoku Population in Summer of 2008 and 2009-2011 with Similar Data from 1995}

In July and August, more than $75 \%$ of females collected had mature öocytes in the Kochi-Nankoku population all in 1995-1997, 2007-2008 and 2009-2011 (Table 2). In 1995-1997 and 2009-2011, females with no mature öocytes occupied only $24 \%-27 \%$ in September, whereas in 2007-2008, the percent diapause reached 70\%90\% in September (Table 2). From April to July, males all in 1995-1997, 2008 and 2009-2011 had mature testes with a testes volume index of more than $400\left(\times 10^{-4}\right)$ $\mathrm{mm}^{3}$ on average (Figure 2) (Table 3). In late May and June when the first generation adults newly appear, males of the Kochi-Nankoku population in 1995 had relatively well-matured and large testes with an average testes volume index of $500-700\left(\times 10^{-4}\right) \mathrm{mm}^{3}$ (Table 3), whereas the testes volume index was very low with an average of less than 200 during the same season in 20092011 (Mann-Whitney U-test between 1995 and 20092011: $\mathrm{z}=-5.68, \mathrm{p}<0.001$ ) (Figure 2) (Table 3). In the second half of August and the first half of September, males had well developed testes with the testis-volume index of $600-1200\left(\times 10^{-4}\right) \mathrm{mm}^{3}$ on average both in 19951997 and 2009-2011. The testis volume in the second half of September was small with $200-300\left(\times 10^{-4}\right) \mathrm{mm}^{3}$ in 2008 and 2009-2011, whereas the testes was well matured with the volume index of $800\left(\times 10^{-4}\right) \mathrm{mm}^{3}$ on average in 1995 (Mann-Whitney U-test between 1995-1997 and 2009-2011: $\mathrm{z}=-3.445, \mathrm{p}=0.001$ ) (Figure 2) (Table 3). In 2009-2011, the first generation males deposited the melanin on the allinotum in accordance with aging dur-

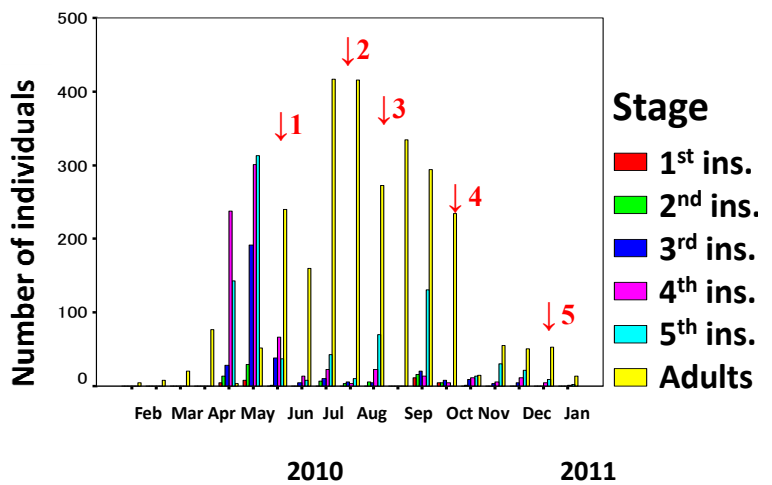

Figure 1. Seasonal variation of the number of individuals at several larval stages and adults collected from a water way in Kochi-Nankoku region (33 N) of Kochi Prefecture, Japan in 2010-2011. Red arrows show the emergence season of new generation of Aquarius paludum.

Table 1. Decrease in individual number of 5th instar larvae in a Kochi-Nankoku population in 2010. A: $\mathrm{N}$ of 5th instar larvae; B: $\mathrm{N}$ of the other larvae and adults.

\begin{tabular}{|c|c|c|c|c|c|c|c|c|c|c|}
\hline & \multicolumn{2}{|c|}{ 1st generation } & \multicolumn{2}{|c|}{ 2nd generation } & \multicolumn{2}{|c|}{ 3rd generation } & \multicolumn{2}{|c|}{ 4th generation } & \multicolumn{2}{|c|}{5 th generation } \\
\hline & May 19 & Jun 3 & Jul 13 & Aug 3 & Aug 24 & Sep 6 & Sep 20 & Oct 10 & Nov 20 & Dec 27 \\
\hline A & 313 & 37 & 43 & 10 & 70 & 0 & 131 & 0 & 30 & 9 \\
\hline \multirow[t]{3}{*}{ B } & 582 & 345 & 456 & 427 & 305 & 335 & 354 & 254 & 64 & 58 \\
\hline & \multicolumn{10}{|c|}{$\mathrm{x}^{2}$-test } \\
\hline & \multicolumn{2}{|c|}{1 st } & \multicolumn{2}{|c|}{ 2nd } & \multicolumn{2}{|c|}{$3 \mathrm{rd}$} & \multicolumn{2}{|c|}{4 th } & \multicolumn{2}{|c|}{5 th } \\
\hline $\mathrm{df}$ & \multicolumn{2}{|c|}{1} & \multicolumn{2}{|c|}{1} & \multicolumn{2}{|c|}{1} & \multicolumn{2}{|c|}{1} & \multicolumn{2}{|c|}{1} \\
\hline$\chi^{2}$ value & \multicolumn{2}{|c|}{86.0} & \multicolumn{2}{|c|}{17.5} & \multicolumn{2}{|c|}{69.4} & \multicolumn{2}{|c|}{83.4} & \multicolumn{2}{|c|}{7.3} \\
\hline $\mathrm{p}$ & \multicolumn{2}{|c|}{$<0.001$} & \multicolumn{2}{|c|}{$<0.001$} & \multicolumn{2}{|c|}{$<0.001$} & \multicolumn{2}{|c|}{$<0.001$} & \multicolumn{2}{|c|}{$<0.007$} \\
\hline
\end{tabular}

Table 2. Comparison among 2009-2011, 2007-2008 and 1995-1997 of \% diapauses in females of the Kochi-Nankoku (K-N) population of a water strider, Aquarius paludum. Values of 2007-2008 and 1995-1997 after Harada et al., (2011) [\%(n)] and Fisher's Exact Probability test. ${ }^{*}: \mathrm{p}<0.05 ;{ }^{* *}: \mathrm{p}<0.01$ (Harada et al., 2011: data for K-N'95 - '97 and K-N'07 - '08).

\begin{tabular}{cccccc}
\hline & Jul & Aug & Sep & Oct & Nov \\
\hline K-N'95 - '97 & $19.40(67)$ & $21.21(33)$ & $24.53(53)$ & $53.57(28)$ & $86.36(22)$ \\
K-N'07 - '08 & - & $0.0(87)$ & $77.27(22)$ & $100.0(10)$ & $100.0(18)$ \\
K-N'09 - '11 & $9.52(42)$ & $21.84(87)$ & $27.03(74)$ & $46.43(28)$ & $60.53(38)$ \\
K-N'95 - '97 vs K-N'07 - '08 p-value & - & 0.314 & $<0.001^{* *}$ & $0.008^{* *}$ & 0.238 \\
K-N'95 - '97 vs K-N'09 - '11 p-value & 0.109 & 0.334 & 0.752 & $0.029^{*}$ & $0.035^{*}$ \\
\hline
\end{tabular}


Table 3. Seasonal variation in the volume index of testes in the Kochi-Nankoku population (1995, 2008 and 2009-2011) of a water strider, Aquarius paludum [Mean $\pm \mathrm{SD}(\mathrm{n}), \times 10^{-4} \mathrm{~mm}^{3}$ ]. The data of 1995 and 2008 after Harada et al. (2011).

\begin{tabular}{|c|c|c|c|c|c|c|}
\hline Year & 1st half Apr & 2nd half Apr & 1st half May & 2nd half May & 1st half Jun & 2nd half Jun \\
\hline 1995 & $810.6 \pm 376.7(8)$ & $950.6 \pm 644.1(16)$ & $870.9 \pm 595.4(13)$ & $582.5 \pm 723.9(26)$ & $673.5 \pm 581.7(31)$ & $516.2 \pm 415.8(15)$ \\
\hline 2008 & $995.0 \pm 504.9(10)$ & $781.5 \pm 586.9(4)$ & - & - & $1309.1 \pm 825.7(8)$ & - \\
\hline $09^{\prime}-11^{\prime}$ & $437.4 \pm 260.8$ & $429.6 \pm 269.8(22)$ & $531.7 \pm 680.8$ & $138.8 \pm 170.9(29)$ & $197.7 \pm 157.9(28)$ & $174.0 \pm 126.3(28)$ \\
\hline Year & 1st half Jul & 2nd half Jul & 1st half Aug & 2nd half Aug & 1st half Sep & 2nd half Sep \\
\hline 1995 & $877.8 \pm 693.6(46)$ & $745.1 \pm 528.5(13)$ & $776.1 \pm 552.6(7)$ & $583.5 \pm 597.0(13)$ & $888.1 \pm 513.3(9)$ & $804.9 \pm 820.2(20)$ \\
\hline 2008 & - & $567.7 \pm 517.7(6)$ & $262.0 \pm 173.4(10)$ & - & - & $293.0 \pm 292.4(9)$ \\
\hline $09^{\prime}-11^{\prime}$ & $270.6 \pm 307.5(24)$ & $347.7 \pm 218.7(17)$ & $351.7 \pm 285.5(28)$ & $1232.2 \pm 2195.8(54)$ & $639.9 \pm 1100.3(40)$ & $196.3 \pm 134.8(37)$ \\
\hline Year & 1st half Oct & 2nd half Oct & 1st half Nov & 2nd half Nov & 1st half Dec & 2nd half Dec \\
\hline 2008 & $194.2 \pm 182.9(9)$ & - & $234.8 \pm 302.7(8)$ & $237.1 \pm 237.0(9)$ & - & - \\
\hline $09^{\prime}-11^{\prime}$ & $159.4 \pm 133.5(24)$ & $15.1 \pm 9.6(5)$ & $97.9 \pm 111.2(23)$ & $36.4 \pm 58.3(21)$ & $56.6 \pm 86.1(9)$ & $116.4(1)$ \\
\hline
\end{tabular}

ing the second half of May and June $\left(\chi^{2}\right.$-test between the second half of May and the second half of June, $\chi^{2}$-value $=14.4, \mathrm{df}=4, \mathrm{p}=0.006)($ Figure 3), while the testis was kept small with the volume index less than $200\left(\times 10^{-4}\right)$ $\mathrm{mm}^{3}$ on average in the same season (Figure 2) (Table 3) (Mann-Whitney U-test, $\mathrm{z}=-1.224, \mathrm{p}=0.221$ ). In the whole, season has significant relationship to the testesvolume index and also the allinotum melanin deposition tended to be related to the testes-volume index in 20092011 (ANCOVA, season on testis-volume with covariance of allinotum melanin deposition: $\mathrm{df}=21, \mathrm{~F}$-value $=3.991, \mathrm{p}<0.001$; allinotum melanin deposition on testis-volume with covatiance of season: $\mathrm{df}=4, \mathrm{~F}$-value $=1.935, \mathrm{p}=0.103)($ Figures 2 and 4$)$.

\subsection{Wing Lengths of Kochi-Nankoku Populations Adults Collected from the Field: Comparison between 1995 and 2009-2011}

In October to November, long-winged adults occupied $67 \%$ of the overwintering adults in 1995, whereas only $40 \%$ were occupied by long-winged adults and instead a mosaic morph with long fore-wing (wing-index of 8 - 13) and short hind-wing (wing-index of $0-6$ ) occupied $30 \%$ of them (Figures 5 and 6) (Table 4).

\subsection{Flight Muscle Condition of Kochi-Nankoku Overwintering Population Adults Collected from the Field: Comparison between 1995 and 2009-2011}

About $70 \%$ of overwintering adults kept well developed flight muscles (Rank 3) in 1995, whereas only $47 \%$ of

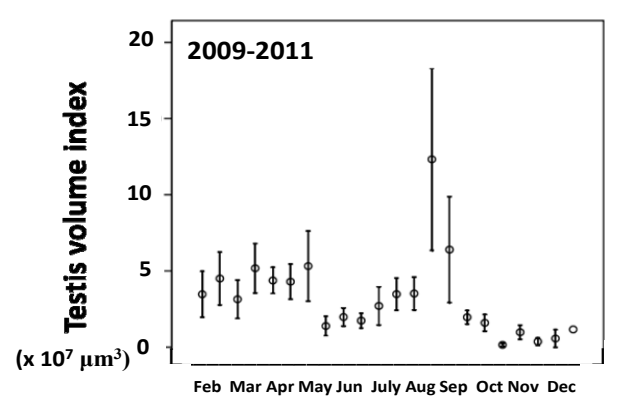

Figure 2. Seasonal variation in testis volume index in the Kochi-Nankoku population in 2009-2011. Testis volume index was expressed as 10,000,000 micro cubic-meter.

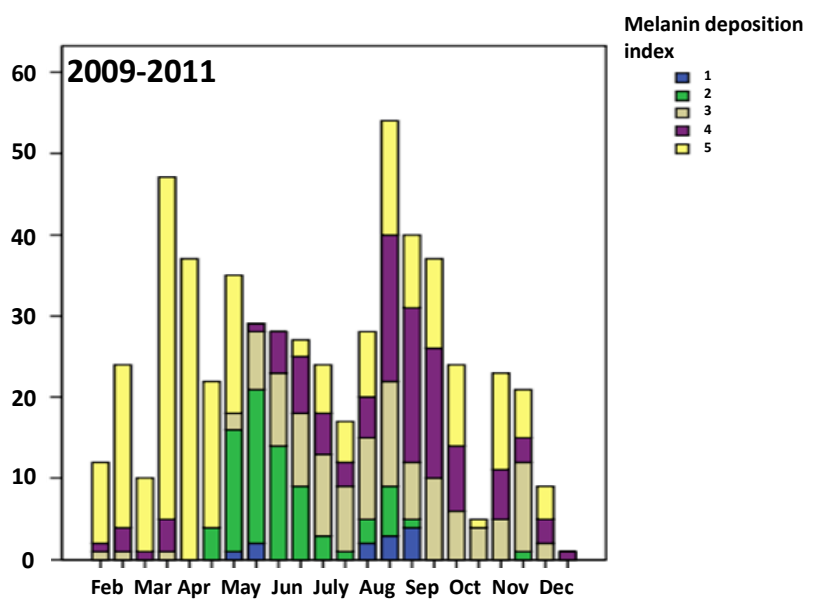

Figure 3. Seasonal variation of the condition of melanin deposition in the allinotum of a water strider, Aquarius paludum collected from the field through the 3 years of 2009-2011. Sufficient melainin deposition could be seen for the overwintered adults in February and April as Andersen (1973) suggested. 


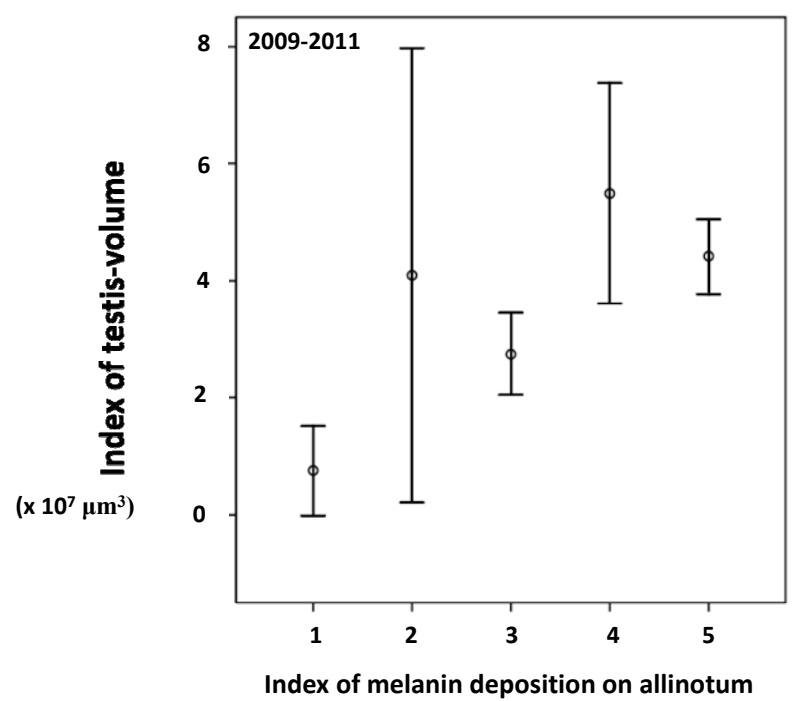

Figure 4. Relationship between the index of melainin deposition on all inotum (cuticle plate underneath the meso-thoracic dorsal cuticle plate) and the index of testis-volume of adult Aquarius paludum collected from the field of the Kochi Nankoku population through the 3 years of 2009-2011. Testis volume index was expressed as 10,000,000 micro cubic-meter.

Females
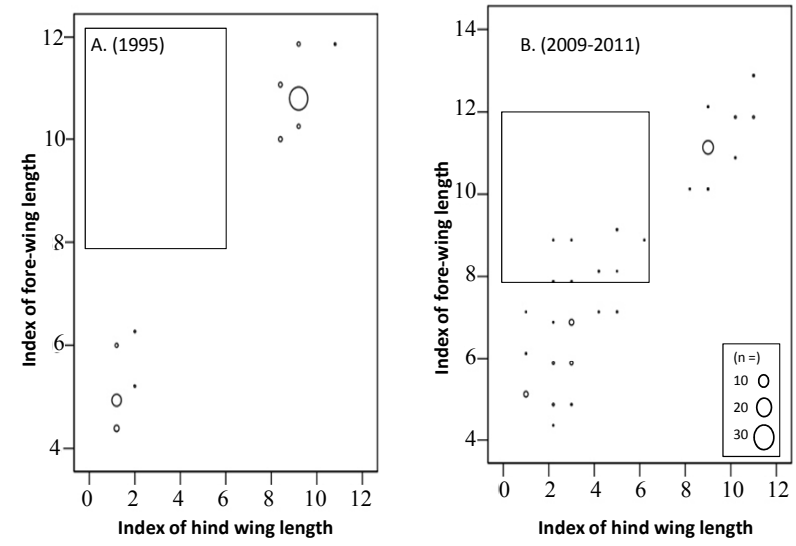

Figure 5. Comparison of fore-wing and hind-wing lengths of the overwintering generation females adults (Oct to Dec) between 1995 (A) and 2009-2011 (B). Most of the adults in 1995 are long-wing morphs or short-wing morphs, while the "Mosaic" morph (within square) with long fore-wings and short hind-wings can be seen in the overwintering population in 2009-2011.
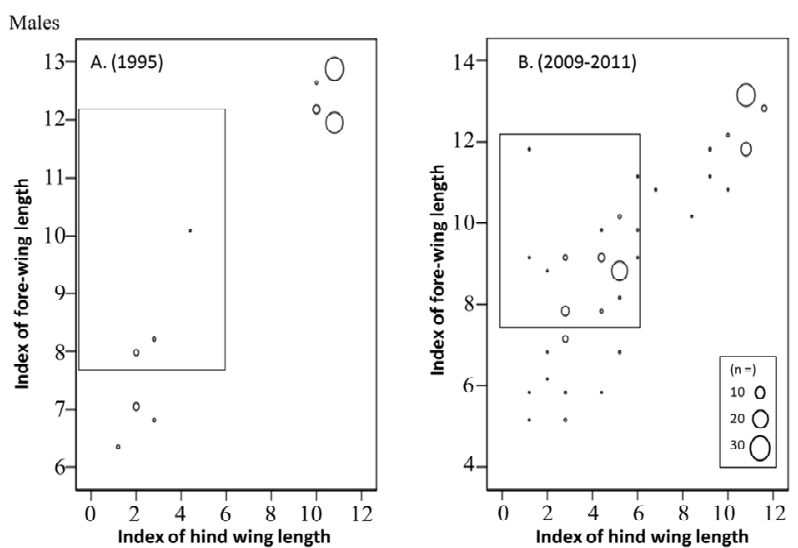

Figure 6. Comparison of fore-wing and hind-wing lengths of the overwintering generation males adults (Oct to Dec) between 1995 (A) and 2009-2011 (B). Most of the adults in 1995 are long-wing morphs or short-wing morphs, while the "Mosaic" morph (within square) with long fore-wings and short hindwings can be seen in the overwintering population in 2009-2011.

them did so in 2009-2011 (Table 5) $\left(\chi^{2}\right.$-test: $\chi^{2}$-value $=16.8, \mathrm{df}=2, \mathrm{p}<0.001)$. Most of overwintering adults with "mosaic" wings with long forewing and short hind wing had immature or histolysed flight muscles (Table 5).

\section{DISCUSSION}

\subsection{Generation Number}

The Kochi-Nankoku population showed tri-voltinismin 1991 [24]. In 2007, the voltine number may have increased to four or more, as the recruitment of new generation adults occurs four times or more as shown by the larval samplings. The generation number in Kochi could be estimated as the five due to the number of peak of appearance of the fifth instar larvae. The fifth instars grow in November and December and $40 \%$ of females are reproductive even in November in 2009-2011. This could suggests that reproduction and following larval development even in the winter would be active even in mid winter in the near future if global warming continues to progress [23].

\subsection{Adult Aestivation}

In 2008, high proportion of males had smaller testes

Table 4. Percent $(\mathrm{N})$ of individuals with long-wing, mosaic-wing (fore wing index: 8 - 13, hind wing index: 0 - 6) and short-wing in the overwintering generation in 1995 and 2009-2011.

\begin{tabular}{cccccc}
\hline \multicolumn{1}{c}{1995} & & $2009-2011$ & \\
\hline Long-winged & Mosaic-winged & Short-winged & Long-winged & Mosaic-winged & Short-winged \\
\hline $67.5(83)$ & $5.7(7)$ & $26.8(33)$ & $44.2(201)$ & $30.3(138)$ & $25.5(116)$ \\
& & $\chi^{2}$-test: $\chi^{2}$-value $=34.20, \mathrm{df}=2, \mathrm{p}<0.001$ & & \\
\hline
\end{tabular}


Table 5. Comparison of flight muscle condition by overwintering adults of Kochi-Nankoku populations of Aquarius paludum between 1995 and 2009-2011. (\% [N]) LW: Long-winged; MW: Mosaic-winged (Long fore-winged and short hind-winged); SW: Short-winged.

\begin{tabular}{|c|c|c|c|c|c|c|c|c|}
\hline & \multicolumn{4}{|c|}{1995} & \multicolumn{4}{|c|}{ 2009-2011 } \\
\hline & \multicolumn{4}{|c|}{ Flight muscle index } & \multicolumn{4}{|c|}{ Flight muscle index } \\
\hline & Rank 1 & Rank 2 & Rank 3 & Total & Rank 1 & Rank 2 & Rank 3 & Total \\
\hline LW & $24.2[15]$ & $6.5[4]$ & $69.4[43]$ & $75.6[62]$ & $17.6[15]$ & $35.3[30]$ & $47.1[40]$ & $41.5[85]$ \\
\hline MW & $100[3]$ & $0[0]$ & $0[0]$ & $3.7[3]$ & $64.8[46]$ & $29.6[21]$ & $5.6[4]$ & $34.6[71]$ \\
\hline SW & $100[17]$ & $0[0]$ & $0[0]$ & $20.7[17]$ & $83.7[41]$ & $16.3[8]$ & $0[0]$ & $23.9[49]$ \\
\hline$\chi^{2}$-test: & \multicolumn{4}{|c|}{$\chi^{2}$-value $=43.3, \mathrm{df}=4, \mathrm{p}<0.001$} & \multicolumn{4}{|c|}{$\chi^{2}$-value $=80.8, \mathrm{df}=4, \mathrm{p}<0.001$} \\
\hline
\end{tabular}

and high proportion of females had no mature öocytes in September, 2008. This smaller testes could be seen in the last half of September also in 2009-2011. Moreover, the first generation males which emerge in the second half of May kept small and immature testes for 30 - 45 days. However, the proportion of females which had no mature öocytes was low in September of 2009-2011. This may suggest that the Kochi-Nankoku population especially males begins to show aestivation very partially. Until 1995, such reproductive suppression in summer had not been seen. Such a new physiological strain adopting aestivation could have a higher fitness than the former strain without aestivation in the future if summer temperatures become significantly higher in the next decade [23]. However, evidence based on adequate laboratory rearing-experiment is remained for the induction and termination of the aestivation in this population.

\subsection{Stopping of Dispersal between Water Bodies and Overwintering Sites on Land Far from Water Bodies}

In 2007, overwintering and overwintered adults had no mature flights muscles [23]. In 2009-2011, only $19.5 \%$ of overwintering adults in Oct-Dec kept apparatus for flights as long-wings and well-developed flight muscles. Moreover, no overwintering females in fall had mature oocytes and all males had small and immature testes in fall of 2008. In 2009-2011, $60 \%$ of overwintering females had no mature öocytes and all the males had very small testis with less than $100\left(\times 10^{-4} \mathrm{~mm}^{3}\right)$. Moreover, only $19.5 \%$ of the overwintering adults had dispersal apparatus as long fore and hind wings and well developed flight muscles with Rank 3 in 2009-2011, whereas $52 \%$ of the overwintering adults did so in 1995 . These phenomena could suggest that adults which are in reproductive diapauses in fall are no longer dispersing between the water bodies and overwintering sites on land far from water bodies. If the winter warming continues in the future, the risk of the death due to low temperatures in winter at overwintering sites could decrease even near the shore and the proportion of adults overwintering near water bodies could increase [23].

In conclusion, these three changes: "increased number of voltine", "newly adopting aestivation" and "overwintering near the shore" would occur due to ongoing meteorological warming in Kochi Prefecture (Kochi Meteorological Station, 1995-2011).

\section{ACKNOWLEDGEMENTS}

Special thanks are due to Kochi University for financial support for the transportation between natural fields (water way in the critical area between Kochi city and Nankoku city in Kochi Prefecture) and the Laboratory of Environmental Physiology, Kochi University.

\section{REFERENCES}

[1] C Hassell, M.P., Godfray, H.C.J. and Comins, H.N. (1993) Effects of global change on the dynamics of insect hostparasitoid interactions. In: Kareiva, P.M., et al., Eds., Biotic Interactions and Global Change, Sinauer, Sunderland, 402-424.

[2] Imura, O., Morimoto, N. and Kiura, T. (1993) Potential effect of global warming on the distribution of insects in Japan. In Kiura, T., Ed., Proceedings of International Symposium on Insect Diversity Research in Korea, Chuncheon, 44-57.

[3] Harrington, R. and Stork, N.E. (1995) Insects in a changing environment. Academic Press, New York.

[4] Kiritani, K. (2001) Insects and climates. Seizando, Tokyo.

[5] Reiter, P. (2008) Global warming and malaria: Knowing the horse before hitching the cart. Malaria Journal, S3, $1-9$.

[6] Schweiger, O., Settele, J., Kudrna, O., Klotz, S. and Kühn, I. (2008) Climate change can cause spatial mismatch of trophically interacting species. Ecology, 89, 3472-3479. doi:10.1890/07-1748.1

[7] Zell, R., Krumbholz, A. and Wurzler, P. (2008) Impact of 
global warming on viral diseases: What is the evidence? Current Opinion in Biotechnology, 19, 652-660. doi:10.1016/i.copbio.2008.10.009

[8] Hegland, S.J., Nielsen, A., La' zaro1, A., Bjerknes, A.-L. and Totland, Ø. (2009) How does climate warming affect plant-pollinator interactions? Ecology Letters, 12, 184195. doi:10.1111/j.1461-0248.2008.01269.x

[9] Kiritani, K. (2011) Impacts of global warming on Nezara viridula and its native congeneric species. Journal of AsiaPacific Entomology, 14, 221-226. doi:10.1016/j.aspen.2010.09.002

[10] Parmesan, C. (1996) Climate and species range. Nature, 382, 765-766. doi: $10.1038 / 382765 \mathrm{a} 0$

[11] Netherer, S. and Schopt, A. (2010) Potential effects of climate change on insect herbivores in European forests - General aspects and the pine processionary moth as specific example. Forest Ecology and Management, 259, 831-838. doi:10.1016/j.foreco.2009.07.034

[12] Ikemoto, T. (2008) Tropical malaria does not mean hot environments. Journal of Medical Entomology, 45, 963969.

doi:10.1603/0022-2585(2008)45[963:TMDNMH]2.0.CO; $\underline{2}$

[13] Paz, S. and Albersheim, I. (2008) Influence of warming tendency on Culex pipiens population abundance and on the probability of West Nile Fever outbreaks (Israeli Case Study: 2001-2005). Eco Health, 5, 40-48. doi:10.1007/s10393-007-0150-0

[14] Massad, E., Antonio, F., Coutinho, B., Fernandez Lopez, L. and da Silva, D.R. (2011) Modeling the impact of global warming on vector-borne infections. Physics of Life Reviews, 8, 169-199.

[15] Wernegreen, J.J. (2012) Mutualism meltdown in insects: Bacteria constrain thermal Adaptation. Current Opinion in Microbiology, 15, 255-262. doi:10.1016/j.mib.2012.02.001

[16] Gomi, T. (2007) Seasonal adaptations of the fall webworm Hyphantria cunea (Drury) (Lepidoptera: Arctiidae) following its invasion of Japan. Ecological Research, 22, 855-861. doi:10.1007/s11284-006-0327-y
[17] Moriyama, M. and Numata, H. (2011) A cicada that ensures its fitness during climate warming by synchronizing its hatching time with the rainy season. Zoological Science, 28, 875-881. doi:10.2108/zsj.28.875

[18] Sgolastra, F., Kempb, W.P., Maini, S. and Bosch, J. (2012) Duration of prepupal summer dormancy regulates synchronization of adult diapause with winter temperatures in bees of the genus Osmia. Journal of Insect Physiology, 58, 924-933. doi:10.1016/j.jinsphys.2012.04.008

[19] Andersen, N.M. (1990) Phylogeny and taxonomy of water striders, genus Aquarius Schellenberg (Insecta, Hemiptera, Gerridae), with a new species from Australia. Steenstrupia, 16, 37-81.

[20] Harada, T. and Numata, H. (1993) Two critical day lengths for the determination of wing forms and the induction of adult diapause in the water strider, Aquarius paludum. Naturwissenschaften, 80, 430-432. doi:10.1007/BF01168342

[21] Inoue, T. and Harada, T. (1997) Lengthening photophase reduces dispersal ability in a water strider, Aquarius paludum (F.). Naturwissenschaften, 84, 306-308. doi: $10.1007 / \mathrm{s} 001140050400$

[22] Harada, T., Nitta, S. and Ito, K. (2005) Photoperiodism changes according to global warming in wing-form determination and diapause induction of a water strider, Aquarius paludum (Heteroptera: Gerridae). Applied Entomology and Zoology, 40, 461-466. doi:10.1303/aez.2005.461

[23] Harada, T., Takenaka, S., Maihara, S., Ito, K. and Tamura, T. (2011) Changes in life-history traits of the water strider Aquarius paludum in accordance with global warming. Physiological Entomology, 36, 309-316. doi:10.1111/j.1365-3032.2011.00798.x

[24] Harada, T., Inoue, T., Ono, I., Kawamura, N., Kishi, M., Doi, K., Inoue, S. and Hodkova, M. (2000) Endocrine, ecophysiological and ecological aspects of seasonal adaptations in a water strider, Aquarius paludum (a mini review). Entomological Science, 3, 157-165.

[25] Kochi Meteorological Station (1995-2011) Annual report of Kochi meteorological station. 